\title{
O EFEITO DAS DICAS NA APRENDIZAGEM DO FOREHAND PARA CRIANÇAS COM CARACTERÍSTICAS DE DÉFICIT DE ATENÇÃO
}

\author{
Isabelle Brusamolin Boell \\ Universidade Federal do Paraná, Curitiba, Paraná, Brasil \\ Andréa Yoshie Silva Yamaguchi \\ Universidade Federal do Paraná, Curitiba, Paraná, Brasil \\ Iverson Ladewig \\ Universidade Federal do Paraná, Curitiba, Paraná, Brasil \\ Adilson Hernandes Spinelli \\ Universidade Federal do Paraná, Curitiba, Paraná, Brasil \\ Luiz Gustavo Cangussú Franz \\ Universidade Federal do Paraná, Curitiba, Paraná, Brasil
}

\begin{abstract}
Resumo
O objetivo do estudo foi verificar a eficácia das dicas de aprendizagem no trabalho com crianças com características de déficit de atenção. Participaram 45 crianças entre 7 e 11 anos, com e sem características de déficit de atenção. A análise dos dados fez uso de testes não paramétricos e a análise descritiva por mediana e desvio padrão. Os resultados indicaram que as crianças com Transtorno de Déficit de Atenção e Hiperatividade (TDAH) que não receberam as dicas obtiveram a pior performance entre os grupos, enquanto as crianças sem TDAH que receberam as dicas apresentaram a melhor performance. Importante destacar que as crianças com TDAH que receberam dicas obtiveram uma performance similar às crianças sem TDAH que também as receberam. Os resultados obtidos pelas crianças com TDAH demonstraram a eficácia das dicas de aprendizagem do forehand com crianças com características de déficit de atenção.
\end{abstract}

Palavras-chave: Aprendizagem. Atenção. TDAH. Tênis.

\section{Introdução}

O principal objetivo do professor quando ensina alguma habilidade ou atividade é fazer com que o aluno aprenda. $\mathrm{O}$ processo ensino-aprendizagem requer que o aluno foque nos pontos importantes da tarefa, o que caracteriza o processo de atenção. O termo "atenção" pode ser definido como o processo que direciona, seleciona, alerta, delibera e contempla (LADEWIG et al., 2001). A atenção tem despertado inúmeros estudos, sendo considerada um processo cognitivo que nos permite controlar estímulos irrelevantes, perceber estímulos importantes e passar de um estímulo para o outro (PORTILHO, 2011). Em outras palavras, a atenção é seletiva. É a habilidade do indivíduo em dirigir o seu foco de atenção para um determinado ponto no ambiente, selecionando estímulos relevantes e ignorando estímulos irrelevantes (LADEWIG et al, 2001; SCHIMDT e WRISBERG, 2008).A atenção seletiva, segundo Ladewig et al. (2001), é dividida em três estágios: exclusivo, inclusivo e atenção 
seletiva. No primeiro estágio (exclusivo), bebês e crianças muito jovens dirigem toda a atenção exclusivamente a um único objeto.

Já no segundo estágio (inclusivo), que se inicia por volta do primeiro ano do ensino fundamental, a criança é facilmente distraída pelas inúmeras informações contidas no meio ambiente, incluindo vários estímulos simultaneamente, não sendo capaz de separar as informações relevantes das irrelevantes.

Por volta dos 11-12 anos de idade, os pré-adolescentes atingem o terceiro estágio (atenção seletiva), quando começam a adquirir a habilidade de direcionar seu foco de atenção para pontos relevantes, descartando itens irrelevantes.

Considerando essas definições, podemos assumir que, nos anos iniciais de escolarização, há a necessidade de utilizarmos estratégias que favoreçam o controle e o direcionamento da atenção (PORTILHO, 2011). O ponto-chave no desenvolvimento contínuo da atenção seletiva é o segundo estágio, por volta dos 5 anos de idade, até próximo dos 10 anos. Neste período, a falta de atenção é considerada um problema, porque as crianças não conseguem direcionar a atenção especificamente a um estímulo e se distraem facilmente. Não há maturidade funcional suficiente para essa percepção, sendo necessárias estratégias que favoreçam o controle e o direcionamento de todo o sistema cognitivo para a informação relevante de cada contexto (PORTILHO, 2011).

Essa dificuldade em prestar atenção torna-se ainda mais delicada no caso de crianças com problemas adicionais no desenvolvimento do foco de atenção, como aquelas com problemas de Transtorno do Déficit de Atenção e Hiperatividade (TDAH).

O TDAH é uma síndrome que afeta de 3\% a 5\% da população infantil, ocasionando dificuldades no rendimento escolar, no relacionamento com outras crianças e no relacionamento com os pais e os professores (JUNOD et al., 2006). Os sintomas variam de acordo com o tipo predominante do TDAH e são assim classificados: 1) sintomas predominantes de desatenção; 2) sintomas predominantes de hiperatividade/impulsividade, e 3) combinados.

É certo que uma criança com essa síndrome apresentará problemas de aprendizagem, pois, segundo Ladewig, Cidade e Ladewig (2001), o processo da atenção é fundamental para a aprendizagem, no sentido de selecionar as informações relevantes e retê-las na memória de longa duração. Assim sendo, um dos objetivos principais do professor no processo ensinoaprendizagem é conseguir captar e manter a atenção da criança, utilizando de estratégias de atenção que facilitem a aprendizagem.

Um exemplo de estratégias de atenção utilizadas em diversas situações de ensinoaprendizagem são "dicas de aprendizagem", ou seja, frases curtas, geralmente compostas por uma ou duas palavras, que direcionam a atenção do sujeito aos aspectos relevantes da tarefa, auxiliando no processo da atenção seletiva. O termo "dicas de aprendizagem" foi escolhido por Ladewig, Cidade e Ladewig (2001) como a melhor tradução do termo inglês "cues". Essa terminologia está incorporada na Educação Física, com diversos estudos realizados nas últimas décadas, com base em diferentes tarefas e populações (LADEWIG, 1994; LADEWIG et al., 2001; BERTOLDI, 2004; CAÇOLA; LADEWIG, 2007; SILVEIRA, 2010; MEDINAPAPST et al., 2010; OKASAKI, 2011; SILVEIRA et al., 2013; BOELL, 2016; FRANZ, 2016; SPINELLI, 2016).

A falta de atenção, dependendo da faixa etária da criança, é um problema não só na escola, mas em casa também. Isso pode se agravar quando essas crianças apresentam características comportamentais de déficit de atenção, definida como uma dificuldade na manutenção da atenção, do controle de impulsos e na regulagem da conduta motriz em resposta às demandas da situação (ARAÚJO; SILVA, 2003).

A desatenção apresenta os seguintes sintomas: não prestar atenção a detalhes ou cometer erros por descuido; ter dificuldade para se concentrar em tarefas ou jogos; parecer 
não escutar quando lhe dirigem a palavra; apresentar dificuldade em seguir regras e instruções; não terminar o que começa; ser desorganizado com as tarefas e materiais; evitar as atividades que exijam um esforço mental prolongado; perder coisas importantes; distrair-se facilmente com coisas que não têm nada a ver com o que está fazendo; e esquecer compromissos e tarefas diárias. Para poder afirmar que a criança tem características comportamentais de desatenção, é preciso que ela apresente pelo menos seis sintomas dos itens citados anteriormente. Normalmente, os sintomas são identificados desde a idade préescolar, ou pelo menos aparecem por um período de vários meses intensamente.

Para caracterizar a desatenção, os sintomas devem estar presentes em vários ambientes da vida da criança, por exemplo, em casa e na escola (PASTURA et al., 2005; ROHDE; BENCZIC, 1999). O maior problema das crianças com sintomas de desatenção não é a dificuldade em prestar atenção, mas, sim, a dificuldade de manter o foco da atenção por períodos mais longos, distraindo-se facilmente por outros estímulos do ambiente, ou seja, o seu freio inibitório para outros estímulos não funciona de maneira adequada (ROHDE; BENCZIC, 1999).

Deste modo, a preocupação dos professores que atuam com essa população específica deve ser a de auxiliar as crianças a captar e a manter a atenção nas atividades que estão sendo desenvolvidas, por exemplo, utilizando dicas de aprendizagem. Assim sendo, o objetivo deste estudo foi verificar a eficácia das dicas de aprendizagem no trabalho com crianças com características de desatenção, durante o processo de ensino do forehand do tênis de campo.

\section{Metodologia}

\section{Sujeitos}

A amostra foi constituída por 45 alunos $(8,66$ anos de idade $\pm 0,87)$, matriculados no ensino fundamental de duas escolas públicas da cidade de Curitiba. As crianças foram divididas em quatro grupos:

1) com desatenção e com dicas: $\mathrm{CdD}(\mathrm{n}=9$ alunos);

2) com desatenção e sem dicas: $\mathrm{CdS}(\mathrm{n}=9$ alunos);

3) sem desatenção e com dicas: $\operatorname{SdD}(n=12$ alunos);

4) sem desatenção e sem dicas: $\operatorname{SdS}$ ( $n=15$ alunos).

A divisão dos grupos foi mantida em sigilo, portanto, as crianças não tiveram acesso à informação sobre quem apresentava características de desatenção e baixo desempenho escolar. Para a realização das aulas e dos testes, as crianças foram separadas apenas em relação ao fator dicas (grupo com dicas e grupo sem dicas).

\section{Procedimentos}

Em um primeiro momento, foram realizadas entrevistas com os professores para que fossem indicados os alunos com baixo rendimento escolar e considerados problemáticos no sentido de falta de atenção nas aulas. Após as entrevistas, foi aplicado o teste DSM-IV (Diagnostic and Statistical Manual of Mental Disorders, ou Manual Diagnóstico e Estatístico de Transtornos Mentais), nos professores e nos pais ou responsáveis dos alunos selecionados. Importante esclarecer que a aplicação dos testes foi realizada pela pesquisadora, com formação em Educação Física, e esses resultados apontam um possível diagnóstico, porém, não podem ser considerados como definitivos para TDAH.

Somente os pais ou responsáveis tiveram acesso aos resultados dos testes com os professores, através de entrevista individual com a pesquisadora. Foram esclarecidos sobre todos os procedimentos da pesquisa e seu processo de aprovação, pelo Comitê de Ética e 
Pesquisa da Universidade Federal do Paraná, sob o número de registro 031-6. Após todos os esclarecimentos, pais ou responsáveis assinaram o Termo de Assentimento Livre e Esclarecido, autorizando seus filhos a participarem do estudo.

Depois da aplicação do DSM-IV, os alunos que apresentaram características comportamentais de TDAH com sintomas predominantes de desatenção nos dois ambientes (escola e casa) realizaram um pré-teste de habilidade no tênis de campo, que confirmou a falta de experiência prévia com o esporte. Após o pré-teste, os alunos participantes deste estudo receberam treinamento durante seis aulas, ministradas três vezes por semana. O objetivo foi o aprendizado da batida de direita do tênis de campo, que é normalmente o primeiro golpe a ser ensinado, conhecido como forehand (ISHIKAZI e CASTRO, 2008). Logo após o término das seis aulas, os alunos realizaram o pós-teste, permanecendo, em seguida, dez dias sem prática. Após esse intervalo de dez dias, todos os alunos realizaram o teste de retenção. Todos os testes (Pré, Pós e Retenção) foram conduzidos exatamente da mesma forma, com os alunos rebatendo 20 bolinhas lançadas pela professora.

Vale destacar que ambos os grupos receberam as instruções básicas para realizar a tarefa, porém, as crianças que estavam nos grupos com dicas receberam dicas para os diferentes fatores técnicos analisados, conforme o Quadro 1.

Quadro 1 - Lista de fatores técnicos analisados e respectivas dicas utilizadas

\begin{tabular}{|c|c|}
\hline FATORES TÉCNICOS & DICAS \\
\hline Empunhadura & Aperto de mão \\
\hline Visualização & Olhar sempre na bola \\
\hline Posicionamento do corpo (Batida Corpo) & Ombro na direção da bola \\
\hline Posicionamento da raquete (Batida Raquete) & "Cara" da raquete para a rede \\
\hline Posicionamento (Espera Corpo) & Posição de goleiro \\
\hline Posicionamento (Espera Quadra) & Arco na posição de espera \\
\hline
\end{tabular}

Fonte: Elaborado pelo autor.

Em cada aula, os alunos tiveram a oportunidade de rebater 50 bolinhas lançadas pela professora, direcionadas a um mesmo local da quadra. As dicas foram fornecidas a cada aula, ou seja: na primeira aula foi fornecida a dica para a empunhadura; na segunda, para a visualização da bola; na terceira, para o posicionamento do corpo para a rebatida; na quarta, para o posicionamento da raquete para a batida; na quinta, para a posição de espera em relação ao corpo e, na sexta aula, para a posição de espera em relação à quadra.

\section{Instrumentos}

Além do Teste DSM-IV, utilizado para identificar os alunos com características comportamentais de desatenção, foi utilizada uma Ficha de Avaliação das Habilidades no Tênis de Campo, criada pela pesquisadora, com o apoio do professor orientador, e validada por dois jogadores expertos em tênis de campo. Esse instrumento foi elaborado para a verificação da aprendizagem nos seis fatores técnicos, através da analise dos vídeos das crianças realizando o movimento. Todos os testes foram filmados, com os vídeos e as fichas de avaliação sendo enviados para três outros professores especialistas na modalidade tênis de campo, os quais atribuíram pontos em cada item. Os vídeos foram enviados para os 
avaliadores de forma aleatória, sem a identificação do tipo de teste (pré-teste, pós-teste ou retenção) e sem a identificação do aluno, os quais eram identificados apenas por números.

A pontuação foi efetuada a partir do preenchimento da ficha de avaliação, cujos escores variavam de 0 a 4 , sendo zero o pior movimento e quatro, um movimento excelente. Os escores obtidos foram utilizados para a análise estatística.

\section{Análise estatística}

Para a análise dos dados, utilizou-se de uma análise descritiva, através da mediana e do desvio padrão. Testes não paramétricos foram utilizados na análise quantitativa, comparando os dados entre os grupos e dentro dos grupos. Para a comparação entre os grupos, foi utilizado o Kruskal-Wallis Test e, para a análise da aprendizagem dentro dos grupos, foi utilizado o Wilcoxon Pairs Test, ambos com nível de significância $p=<0,05$, empregando-se o programa Statistica 7.

\section{Resultados}

No fator técnico "empunhadura", os resultados encontrados na comparação entre os grupos no pós-teste demonstraram que o grupo $\mathrm{SdD}$ apresentou melhores resultados no desempenho em relação aos grupos $\operatorname{CdS}(\mathrm{p}=0,026)$ e $\mathrm{SdS}(\mathrm{p}=0,0189)$. Porém, na retenção, não foram observadas diferenças entre os grupos, já que o grupo SdD não manteve o mesmo desempenho do pós-teste, apresentando uma queda nos resultados.

Gráfico 1 - Escores dos grupos no fator técnico Empunhadura

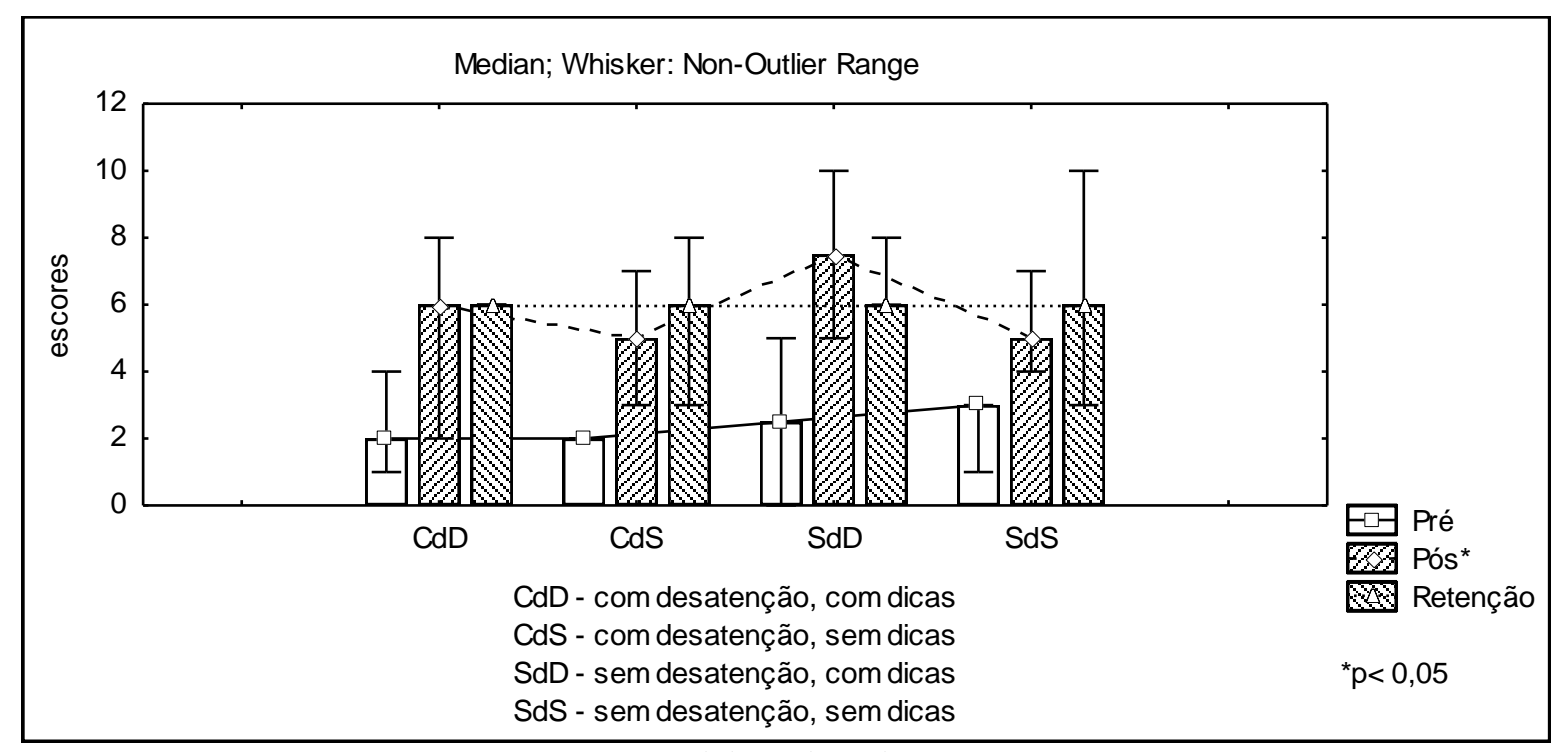

Fonte: Elaborado pelo autor.

Em relação ao fator técnico "visualização", os resultados obtidos pelos grupos mostraram que o grupo $\mathrm{SdD}$ apresentou um melhor desempenho em relação aos grupos $\mathrm{CdS}$ $(\mathrm{p}=0,003)$ e CdD $(\mathrm{p}=0,021)$. Um ponto importante a ser observado na análise dos resultados desse fator foi a queda significativa nos resultados do pós-teste para a retenção do grupo CdD $(\mathrm{p}=0,027)$, como demonstra o Gráfico 2. Após o pós-teste, esse grupo apresentava um 
desempenho próximo aos grupos sem as características de desatenção, mas, após um período sem realizar a prática, demonstrou uma queda no desempenho, ficando com resultado semelhante ao grupo CdS.

Gráfico 2 - Escores dos grupos no fator técnico Visualização

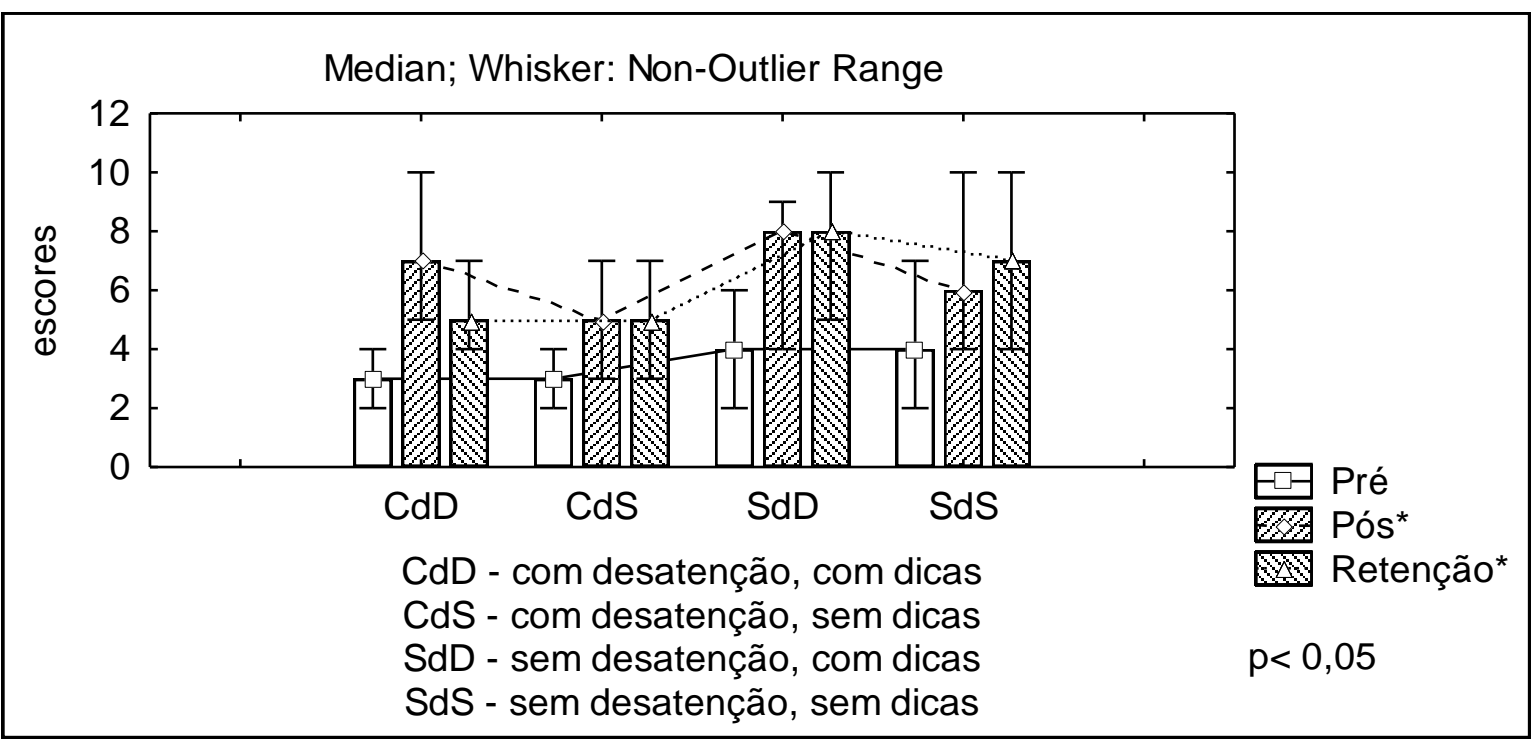

Fonte: Elaborado pelo autor.

No fator técnico "batida corpo", os resultados obtidos no pós-teste demonstraram que o grupo $\mathrm{CdD}$ alcançou melhor desempenho no movimento em relação ao grupo $\mathrm{CdS}(\mathrm{p}=$ 0,030 ), o mesmo acontecendo com o grupo $\mathrm{SdD}$, que apresentou um desempenho superior ao grupo $\mathrm{CdS}(\mathrm{p}=0,008)$. Na retenção, foi verificado que a superioridade do grupo $\mathrm{SdD}$ em relação ao grupo CdS foi mantida $(p=0,005)$, mas não foi encontrada diferença significativa entre os grupos $\mathrm{CdD}$ e $\mathrm{CdS}$.

Gráfico 3 - Escores dos grupos no fator técnico Batida Corpo

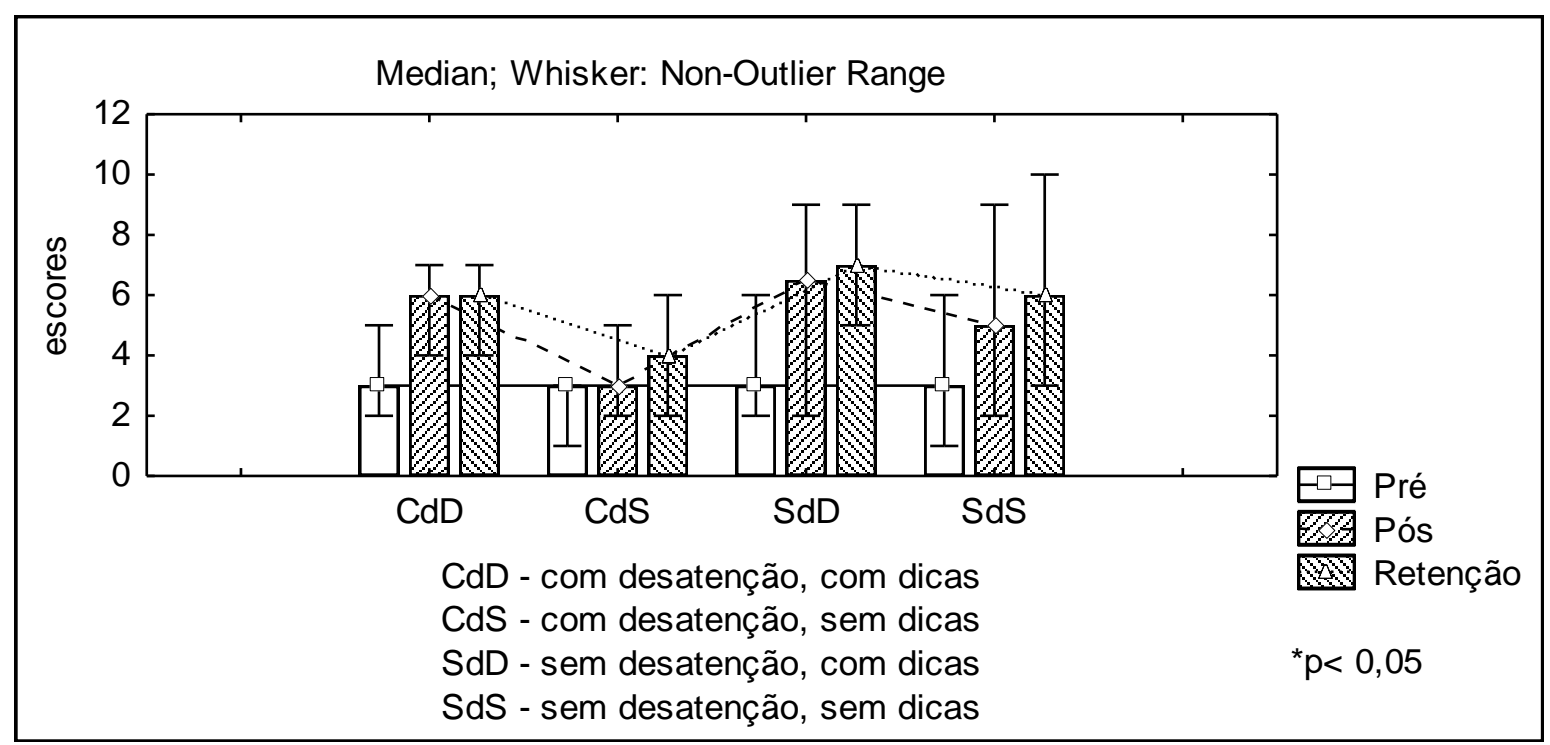

Fonte: Elaborado pelo autor. 
Em relação ao fator técnico "batida raquete", a partir da análise dos resultados dos grupos obtidos no pós-teste, verificou-se que o grupo SdD obteve um desempenho superior ao grupo CdS $(p=0,001)$, mantendo essa superioridade na retenção $(p=0,003)$. No entanto, o aumento dos escores na retenção é observado também nos grupos $\mathrm{CdS}$ e $\mathrm{SdS}$, confirmando que houve uma evolução na aprendizagem. Na comparação entre os demais grupos, não foram encontradas diferenças significativas.

\section{Gráfico 4 - Escores dos grupos no fator técnico Batida Raquete}

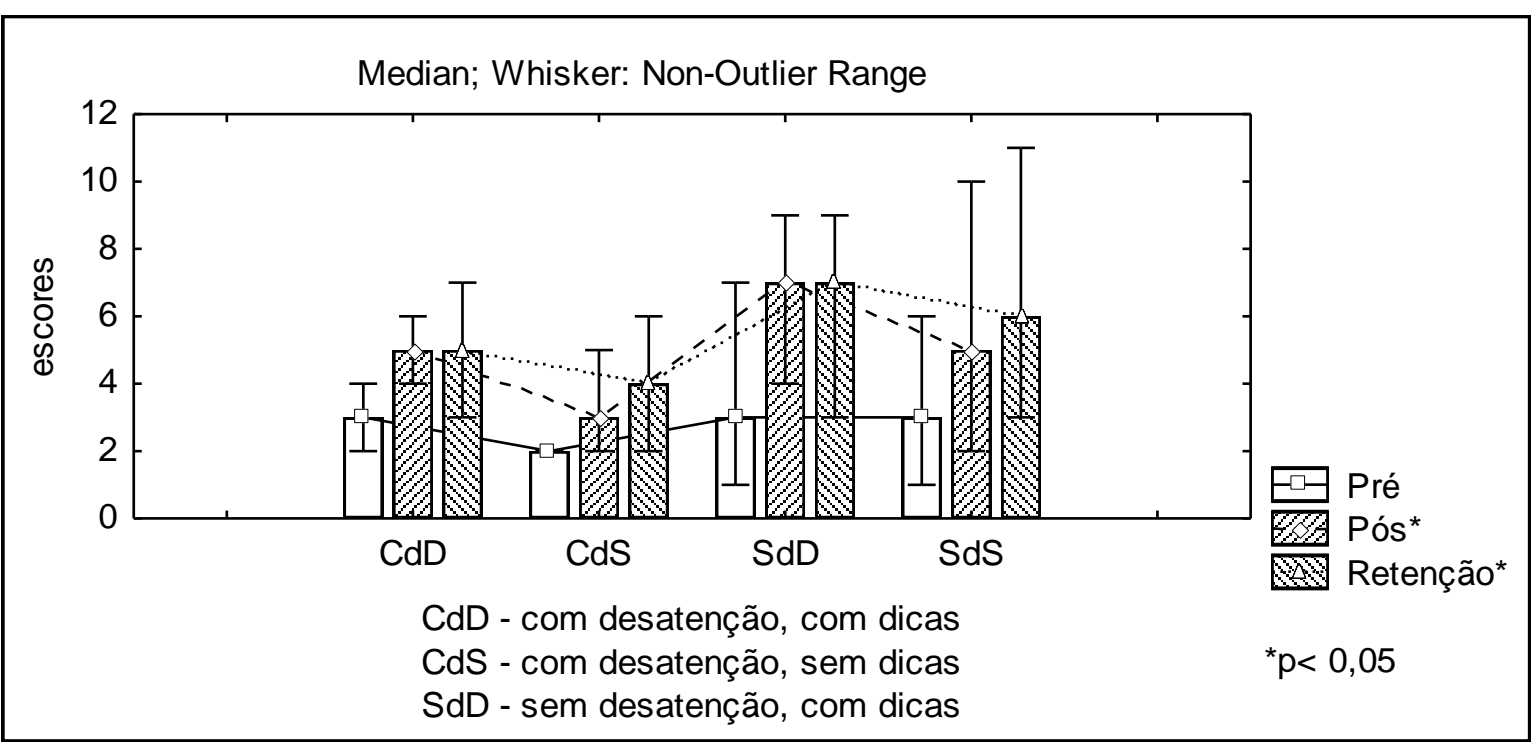

Fonte: Elaborado pelo autor.

No fator técnico "espera corpo", a comparação entre os grupos no pós-teste mostrou um desempenho superior do grupo $\mathrm{SdD}$ em relação ao grupo $\mathrm{CdS}(\mathrm{p}=0,015)$, não ocorrendo diferenças significativas entre os demais grupos. Na retenção, o grupo SdD manteve a diferença significativa para o grupo $\mathrm{CdS}(\mathrm{p}=0,021)$. O grupo $\mathrm{CdD}$ conseguiu manter resultados próximos aos dois grupos, sem características de desatenção. Com base na diferença encontrada entre os grupos SdD e SdS, pode-se inferir que, nesse fator técnico, as dicas de aprendizagem proporcionaram diferença significativa na aprendizagem dos dois grupos sem as características de desatenção. Ambos os grupos que não receberam as dicas evoluíram, ou seja, apenas com a prática e instrução técnica houve aprendizado. 
Gráfico 5 - Escores dos grupos no fator técnico Espera Corpo

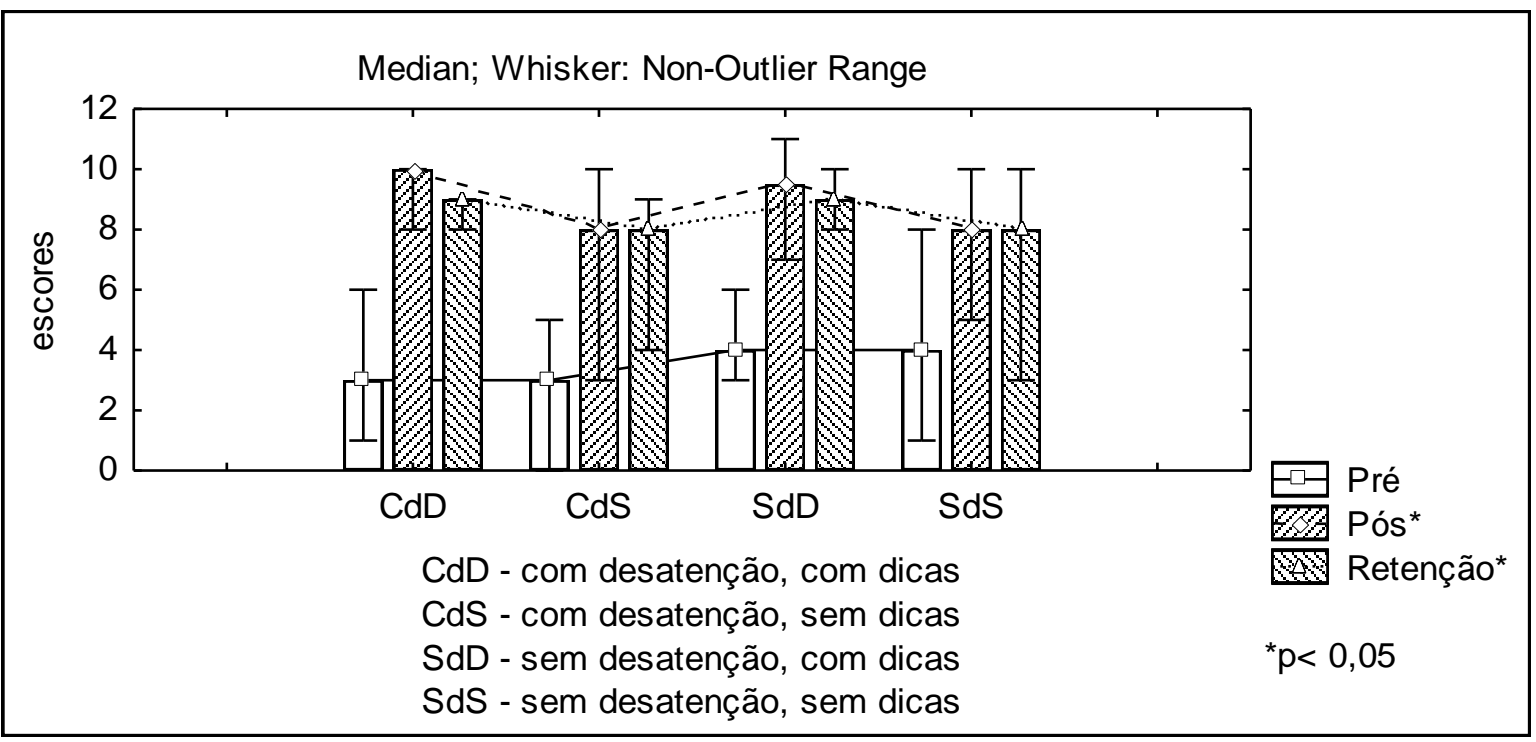

Fonte: Elaborado pelo autor.

Para finalizar, no fator técnico "espera quadra", na análise do desempenho do movimento dos grupos no pós-teste, observou-se que o grupo $\mathrm{CdS}$ obteve resultados significativamente inferiores aos grupos $\operatorname{SdD}(p=0,002)$ e $\mathrm{CdD}(\mathrm{p}=0,035)$. Na retenção, o grupo $\mathrm{SdD}$ apresentou um desempenho significativamente superior aos grupos $\mathrm{CdS}(\mathrm{p}=0,001)$ e $\mathrm{SdS}(\mathrm{p}=$ 0,010). Na comparação entre os grupos com características de desatenção, verificou-se que o grupo CdD não conseguiu os mesmos resultados do pós-teste, sofrendo uma pequena queda no desempenho do movimento e não mantendo a diferença para o $\mathrm{CdS}$, diferente dos dois grupos que não receberam as dicas e mantiveram o desempenho na retenção. Isso sugere que a prática foi suficiente para aprender a habilidade e nem tanto o uso das dicas, mas, observando a retenção, o grupo que recebeu as dicas obteve uma queda na retenção. Um dos motivos pode ser a eficiência da dica não ter se apresentado eficaz a ponto de fazer com que fosse memorizada, já que nos testes não eram fornecidas quaisquer instruções. 
Gráfico 6 - Escores dos grupos no fator técnico Espera Quadra

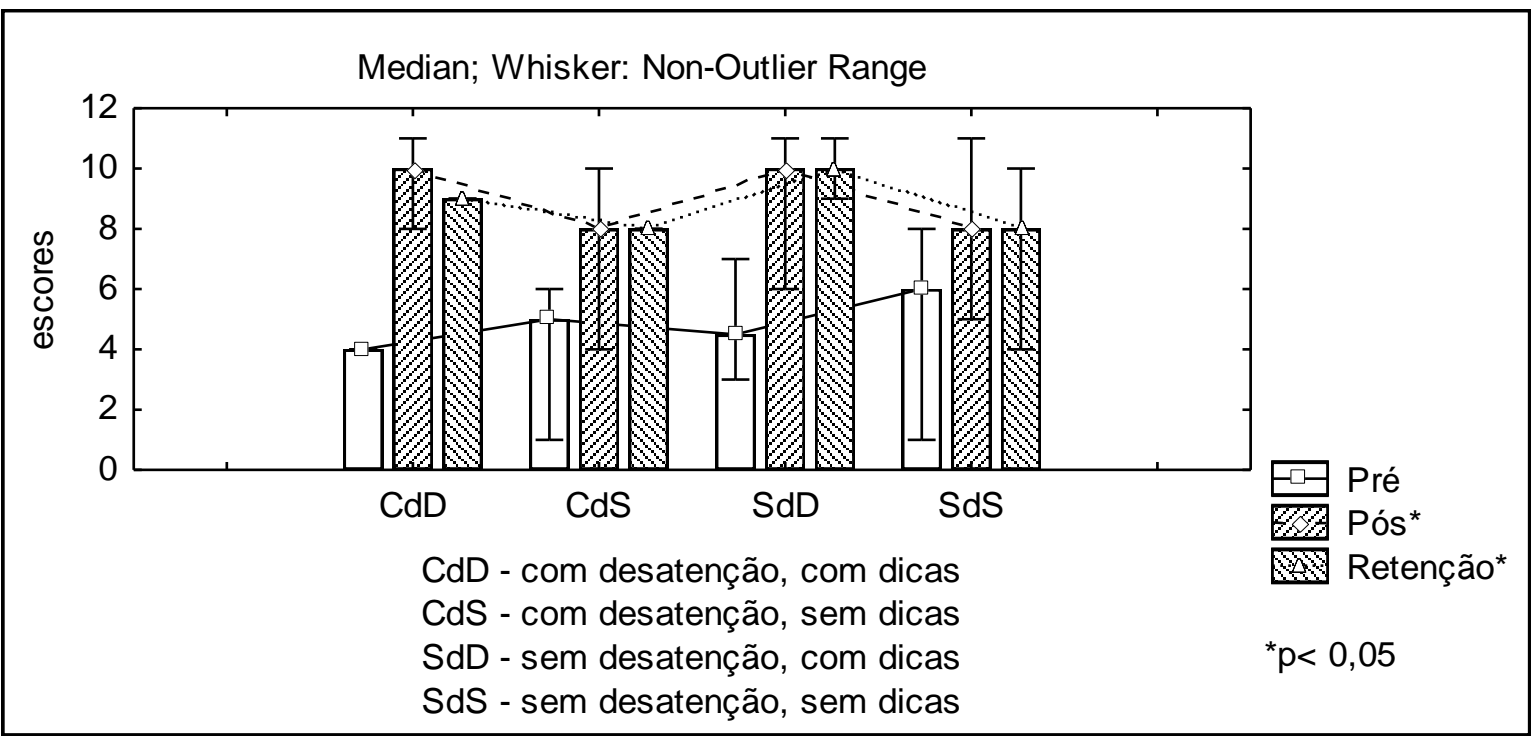

Fonte: Elaborado pelo autor.

\section{Discussão}

O objetivo deste estudo foi verificar a eficácia das dicas de aprendizagem no trabalho com crianças com características de desatenção, durante o processo de ensino do forehand do tênis de campo. Com isto em mente, podemos dizer que os grupos com dicas sem características de desatenção tiveram um resultado superior na maioria dos fatores técnicos estudados, corroborando Boell (2016), que fez uso da mesma atividade, porém com crianças tidas como "típicas".

Entretanto, neste estudo, a aprendizagem ocorreu em todos os grupos, Através dos dados obtidos, de todos os fatores técnicos. Esse resultado vai ao encontro de Ladewig (2001), o qual afirma que todos são capazes de aprender através da prática do movimento, entretanto, o papel das dicas de aprendizagem é o de facilitar e proporcionar uma aprendizagem mais rápida e eficiente para os alunos.

Portanto, as diferenças encontradas entre os grupos referem-se a um melhor desempenho do movimento de um grupo em relação ao outro. Durante a realização dos testes, de maneira geral, foram observadas variações no desempenho dos alunos. Essas variações podem ser explicadas pelo fato de que todos os participantes eram iniciantes na modalidade tênis de campo, portanto, classificados como estando no estágio inicial da aprendizagem, caracterizado por grandes variações no desempenho.

$\mathrm{Na}$ análise dos resultados do fator técnico empunhadura, a ausência de diferenças significativas entre os grupos pode ser explicada pela própria condição do movimento, de fácil assimilação e pouca variação durante a sua execução. Por outro lado, o fator visualização, ou seja, o ato de manter a visão na bolinha, foi um fator técnico no qual observou-se uma grande dificuldade dos grupos com características de desatenção, mesmo fazendo uso das dicas de aprendizagem. Uma provável explicação para a dificuldade encontrada pelos sujeitos pode ser dada pelos requerimentos da tarefa, a qual exige uma grande quantidade de atenção para o sucesso do movimento. A falta de experiência com o tênis de campo, somada às características de desatenção, dificultou assim ainda mais a capacidade de manter a atenção por um longo período de tempo, conforme citam Rodhde e Benczic (1999).

Um ponto importante observado na análise dos resultados da visualização foi a queda significativa $(\mathrm{p}=0,027)$ no desempenho da retenção em relação ao pós-teste do grupo CdD. Esse comportamento demonstra que, dependendo da atividade, não basta apenas fornecer as dicas de aprendizagem e interromper o seu uso assim que o aluno demonstra uma melhora no 
desempenho. No caso de crianças com problemas de desatenção, é importante que haja um reforço constante com as dicas, até que se tenha certeza de que a aprendizagem ocorreu.

Nos fatores técnicos batida corpo e batida raquete, apesar de não terem sido encontradas diferenças significativas, entre os grupos $\mathrm{CdD}$ e $\mathrm{CdS}$ e os grupos $\mathrm{SdD}$ e $\mathrm{SdS}$, é importante ressaltar que as dicas de aprendizagem demonstraram uma tendência positiva pelo fato de o grupo CdD conseguir apresentar um desempenho semelhante aos grupos SdD e SdS. O mesmo efeito aconteceu com os fatores técnicos espera corpo e espera quadra, ou seja, além da diferença entre os grupos $\mathrm{SdD}$ e $\mathrm{SdS}$, novamente o grupo CdD conseguiu apresentar um desempenho próximo ao grupo $\mathrm{SdD}$. Podemos inferir que estes resultados poderiam ser significativos, caso tivéssemos um " $n$ " maior, com a mesma quantidade de sujeitos nos grupos, facilitando a aplicação de um outro procedimento estatístico. Esse problema foi encontrado por Franz (2016), em um estudo que observou o uso de dicas com sujeitos classificados com deficiência intelectual, realizando a atividade de arremesso sobre o ombro. Em primeiro lugar, o " $n$ " era relativamente pequeno e desigual. Seguido de uma grande variação entre todos os sujeitos, de ambos os grupos, e somado à dificuldade de compreensão das dicas, esse fator fez com que não encontrássemos resultados significativos em favor do grupo dicas, mas uma tendência de resultados positivos, quando comparados ao grupo sem dicas.

Ao realizar uma comparação entre os fatores técnicos estudados, pode-se perceber que o desempenho da batida corpo e batida raquete melhorou não só pelo uso das dicas, mas também pelas informações que o próprio movimento fornecia através da prática e que era percebido através do intrínseco, ocasionando uma menor diferença de desempenho entre os alunos dos grupos dicas e sem dicas. Já nos fatores espera corpo e espera quadra, somente através do feedback intrínseco e da quantidade de prática não foi possível realizar os movimentos corretamente. Nesses dois fatores técnicos, o aluno dependia das informações do professor para posicionar seu corpo e ocupar seu lugar na quadra de maneira correta. A explicação técnica para a posição de espera é bem específica e com muitos detalhes. O local correto para posicionar-se na quadra, quando não é fornecido um ponto de referência, acaba se tornando uma informação subjetiva. Esses fatores terminam por gerar dificuldades na performance para os alunos que não receberam as dicas.

Portanto, pode-se observar uma relação inversa entre o feedback intrínseco e as dicas de aprendizagem, em outras palavras, quanto maior a influência da utilização do feedback intrínseco na realização do movimento, menor a importância das dicas, e, quanto menor a participação do feedback intrínseco, maior a importância das dicas.

Para a verificação da eficiência das dicas de aprendizagem, ao realizar a comparação entre os grupos, pôde-se observar que as crianças com características de desatenção obtiveram resultados semelhantes às crianças sem características de desatenção em cinco dos seis fatores técnicos estudados. Portanto, é correto inferir que as dicas de aprendizagem demonstraram resultados positivos para a aprendizagem, no trabalho com crianças com características de desatenção, realizando movimentos do tênis de campo. É importante ressaltar que, apesar de ambos os grupos evoluírem, o que se nota é uma tendência dos grupos que receberam as dicas de apresentar um desvio padrão menor, o que significa uma performance mais consistente do que os que não receberam dicas. Esses resultados corroboram um recente estudo realizado por Boell (2016), com crianças do ensino fundamental, utilizando também o tênis de campo e reaplicando diversos conceitos do presente estudo. A autora (BOELL, 2016) concluiu que a retenção aumentou, na maioria dos fatores técnicos, destacando a superioridade do grupo com dicas no pós-teste e retenção.

Deste modo, pode se destacar ainda que a aprendizagem está diretamente relacionada com a motivação dos alunos em querer aprender. Foi verificado que nas atividades com o tênis de campo, uma modalidade esportiva na qual as crianças não tiveram oportunidade de praticar, todas apresentaram um alto grau de motivação durante as aulas. Esse fato também 
pode ser destacado como positivo no sucesso da aprendizagem de todos os grupos participantes do estudo.

Portanto, ao planejar suas aulas, tanto os professores de Educação Física quanto os professores regentes de classe devem considerar esse fato, deixando de lado um pouco as aulas tradicionais para tentar captar a atenção dos alunos com atividades mais agradáveis e diversificadas. O sucesso da criança na escola é responsabilidade de todos, seja os pais e os professores, seja a equipe pedagógica e também os professores de Educação Física, que não podem e não devem ficar à margem desse processo. Medina-Papst et al. (2011) enfatiza que a aplicação de estratégias de aprendizagem, como as dicas, deve ser um aspecto relevante em diferentes populações durante o processo de ensino-aprendizagem, aqui mais especificamente, com crianças com características de desatenção. Já Silveira et al. (2013) destaca que, para as dicas serem efetivas, devem estar atreladas à especificidade da atividade, focando no elemento essencial para a performance.

Por fim, provavelmente o ponto mais relevante deste estudo é que, dependendo da atividade que estamos ensinando e principalmente, o tipo de população envolvida, não basta apenas fornecer as dicas de aprendizagem, cessando o fornecimento assim que acharmos que o aluno demonstra uma melhora no desempenho. No caso de crianças com problemas de desatenção, é importante que haja um reforço constante com as dicas, até que tenhamos certeza de que a aprendizagem ocorreu.

Os resultados desta pesquisa abrem espaço para que futuros estudos sobre dicas de aprendizagem com crianças com características de desatenção sejam realizadas em outros ambientes e com outras habilidades, tanto na área motora como na área cognitiva.

\title{
THE EFFICIENCY OF USING CUES WHILE LEARNING THE FOREHAND BY CHILDREN WITH ATTENTION DEFICIT CHARACTERISTICS
}

\begin{abstract}
The objective of this study was to verify the learning cues efficacy while working with children with ADDH (Attention Deficit Hyperactivity Disorder). Forthy five children, age ranging from 7 to 11 years were selected to participate. Non parametric tests, median and standard diviation descriptive analysis were used for statistical purposes. The results have demonstrated that children with ADDH which did not receive cues had the worst performance among the groups, while those without ADDH that received cues had the best performance. On the other hand, children with ADDH that received cues had similar performance to those without ADDH that also received cues. The results obtained by the children with ADDH have shown the learning cues efficacy while working with this type of population.
\end{abstract}

Keywords: Learning. Atenttion. ADDH. Tennis.

\section{EL EFECTO DE LAS INSTRUCCIONES EN EL APRENDIZAJE DE FOREHAND EN NIÑOS CON CARACTERÍSTICAS DE DÉFICIT DE ATENCIÓN}

\section{Resumen}

El objetivo del estudio fue verificar la eficacia de las instrucciones de aprendizaje en el trabajo con niños con características de déficit de atención. Participaron 45 niños, de entre 7 y 11 años, con y sin características de déficit de atención. En el análisis de los datos se usaron pruebas no paramétricas y análisis descriptivo por mediana y por desviación estándar. Los resultados indicaron que niños con TDAH (Trastorno de Hiperactividad con Déficit de Atención) que no recibieron las instrucciones obtuvieron los peores resultados entre los grupos, mientras que los niños sin TDAH que recibieron las instrucciones tenían el mejor rendimien- 
to. Es importante destacar que los niños con TDAH que recibieron instrucciones obtuvieron un rendimiento similar al de los niños sin TDAH que recibieron instrucciones. Los resultados obtenidos por los niños con TDAH demostraron la eficacia de las instrucciones do forehand con los niños con características de déficit de atención.

Palabras clave: Aprendizaje. Atención. TDAH. Tenis.

\section{Referências}

ARAÚJO, M; SILVA, S. A. P. S. Comportamento indicativo de déficit de atenção e hiperatividade em crianças: alerta para pais e professores. EF Deports, Buenos Aires, v. 9, n. 62, p. 149-163, jul. 2003.

BERTOLDI, A.S. A influência do uso de dicas de aprendizagem na percepção corporal de crianças portadoras de deficiência motora. 2004. 103 f. Dissertação (Mestrado em Educação Física) - Departamento de Educação Física, UFPR, Curitiba, 2004.

BOELL, I. B. Tênis de campo na escola: a utilização de dicas de aprendizagem visando melhorar o foco de atenção em alunos do ensino fundamental. 2016. 128f. Dissertação (Mestrado Profissional em Educação) - Departamento de Educação, Universidade Federal do Paraná, Curitiba, 2016.

CAÇOLA, P.M.; LADEWIG, I. Comparação entre as práticas em partes e como um todo e a utilização de dicas de aprendizagem de uma habilidade da ginástica rítmica. Revista Brasileira de Ciência e Movimento, v. 15, n. 4, p. 79-86, 2007.

FRANZ, L.G. O uso de dicas de aprendizagem na aquisição de habilidades motoras pelo deficiente intelectual. 2016. 131 f. Dissertação (Mestrado Profissional em Educação) - Departamento de Educação, UFPR, Curitiba, 2016.

ISHIZAKI, M.T.; CASTRO, M. Tênis: aprendizagem e treinamento. 2. ed. São Paulo: Phorte, 2008.

JUNOD, E.; DUPAUL, G. J.; JITENDRA, A. K.; VOLPE, R. J.; CLEARY, K. S. Classroom observations of students with and without ADHD: diferences across types of engagement. Journal of School of Psychology, v. 44, p. 87-104. 2006.

KNAPP, P.; RHODE, L., A.; LYSZKOWSKI, L.; JOHANNPETER, J. Terapia cognitivocomportamental no transtorno do déficit de atenção/hiperatividade: manual do terapeuta. Porto Alegre: Artmed, 2002.

LADEWIG, I. Use of task specific cues and manipulation of environmental distractors to enhance childrens Selective Attention. 1994. Tese (Doutorado) - University of Pittsburgh, Pittsburgh, PA, 1994.

LADEWIG, I. Importância da atenção na aprendizagem de habilidades motoras. Revista Paulista de Educação Física, s. 3, p. 62-71, 2001. 
LADEWIG, I.; CIDADE, R. E.; LADEWIG, M. J. Dicas de aprendizagem visando aprimorar a atenção seletiva em crianças. In: TEIXEIRA, L. A. (Org.) Avanços em comportamento motor. Rio Claro: Movimento, 2001, p. 166-197.

MEDINA-PAPST, J.; CANDIDO, C.R.C.; XAVIER FILHO, E. O efeito de uma estratégia de atenção na aprendizagem do salto em distância. Revistas Científicas de América Latina, el Caribe, España y Portugal - Motricidade, v. 6, n. 4, p. 3-11, 2010.

MEDINA-PAPST, J.; YAMAGUCHI, A.Y.S.; LADEWIG, I. O uso de estratégias de aprendizagem no ensino especial. Revista Pensar a Prática, Goiânia, v.14, n. 2, p. 1-14, maio/ago., 2011.

OKASAKI, N.K. Dicas de aprendizagem fornecidas pelo professor e formuladas pelas crianças no ensino toque e saque por baixo do voleibol. $2011.97 \mathrm{f}$. Dissertação (Mestrado em Educação Física) - Departamento de Educação Física, Universidade Federal do Paraná, Curitiba, 2011.

PASTURA. G. M. C.; MATTOS, P.; ARAÚJO, A. P. Q. C. Desempenho escolar e transtorno do déficit de atenção e hiperatividade. Revista Psiquiatria Clínica, v. 32, n. 6, p. 324-329, 2005.

PORTILHO, E.M.L. (Org.) Alfabetização: aprendizagem e conhecimento na formação docente. Curitiba: Champagnat, 2011.

ROHDE, L. A.; BENCZIC, E. B. Transtorno de déficit de atenção/Hiperatividade - O que é? Como ajudar?. Porto Alegre: Artes Médicas, 1999.

SCHMIDT, R. A.; WRISBERG, C. Aprendizagem e performance motora: uma abordagem baseada no problema. Porto Alegre: Artmed, 2008.

SILVEIRA, C.A. Efeito de dicas de aprendizagem internas e externas, no ensino da habilidade motora "voltas e voltas" com o ioiô. 2010. 109 f. Dissertação (Mestrado em Educação Física) - Departamento de Educação Física, Universidade Federal do Paraná, Curitiba, 2010.

SILVEIRA, S.R.; BASSO, L.; FREUDENHEIN, A.M.; CORREA, U.C. FERREIRA, M.G., TANI, G. Aquisição da habilidade motora de rebater na Ed. Física escolar: um estudo das dicas de aprendizagem como conteúdo de ensino. Revista Brasileira Educação Física e Esporte, v. 27, n. 1, p. 149-157, jan./mar., 2013.

SPESSATO, B.C.; VALENTIN, N. C. Estratégias de ensino nas aulas de dança: demonstração, dicas verbais e imagem mental. Revista Educação Física UEM, v. 24, n. 3, p. 475-487, 2013.

SPINELLI, A. H. O uso de dicas de aprendizagem no processo de ensino de habilidades motoras com crianças do primeiro ano do Ensino Fundamental. 2016. 103 f. Dissertação (Mestrado Profissional em Educação) - Departamento de Educação, Universidade Federal do Paraná, Curitiba, 2016. 
Recebido em: 20/06/2016

Revisado em: 31/07/2016

Aprovado em: 10/04/2017

Endereço para correspondência:

isabellebs@yahoo.com.br

Isabelle Brusamolin Boell

Universidade Federal do Paraná

Rua XV de Novembro, 1299

Centro, Curitiba - PR, 80060-000 